\title{
Ricinoleic Acid Effect on the Electrical Activity of the Small Intestine in Rabbits
}

\author{
John R. Mathias, Joanne L. Martin, and Theodore W. Burns, Veterans \\ Administration Hospital, Gainesville, Florida 32602 and Department of \\ Medicine, College of Medicine, University of Florida, Gainesville, Florida 32610 \\ Gerald M. Carlson and Robert P. Shields, Departments of Pharmacology and \\ Comparative Pathology, College of Veterinary Medicine, University of Florida, \\ Gainesville, Florida 32610
}

A BSTRACT Using myoelectric recording techniques, we examined the myoelectric effects of castor oil; ricinoleic acid (cis isomer), the active ingredient of castor oil; and ricinelaidic acid (trans isomer) in the small intestine of New Zealand white rabbits.

Ricinoleic acid, $2 \mu \mathrm{g} / \mathrm{kg}$ per $\min (6 \mathrm{mM})$, was perfused into a distal 12 -cm ileal loop. An abnormal myoelectric pattern developed that was similar to the alteration in the electrical activity that has previously been reported for cholera enterotoxin. Castor oil, 0.85 $\mathrm{ml} / \mathrm{kg}$, had a similar effect. Ricinelaidic acid, $2 \mu \mathrm{g} / \mathrm{kg}$ per min, induced no activity. A second preparation consisted of an intraluminal perfusion of ricinoleic acid, $2 \mu \mathrm{g} / \mathrm{kg}$ per min, into the first section of the duodenum. The abnormal myoelectric pattern was observed in the jejunum and the ileum but not the duodenum. The mean onset time for the development of this altered myoelectric state for all experiments was $3.5 \mathrm{~h}$.

These studies suggest that an active motility component in addition to the secretory state exists throughout the small intestine that is exposed to castor oil or ricinoleic acid.

\section{INTRODUCTION}

Castor oil, as well as its active ingredient, ricinoleic acid, is regarded as an "irritant" or "stimulant" laxative $(1,2)$. Ricinoleic acid, $2 \mathrm{mM}$, has been shown to alter intestinal ion transport and water flux (3-6) without a demonstrable change in the mucosal architecture $(3,7)$. Recent studies with higher concentrations of ricinoleic acid, $8-10 \mathrm{mM}$, have shown

This work appeared in abstract form: 1976. Clin. Res. 25: 314 A.

Received for publication 15 July 1977 and in revised form 3 November 1.977. alterations in the villous tips by light and electron microscope examination (8-10). In addition, the tight junctions have been shown to remain intact when lanthanum is used (8). Because of these effects of ricinoleic acid on ion transport and its concomitant water flux, some have seriously questioned whether the acid has any irritant or stimulant effect on gastrointestinal smooth muscle at all (11).

We have recently reported that an alteration in myoelectric activity developed in the small intestine of New Zealand white rabbits when exposed to cholera enterotoxin $(12,13)$. This alteration in myoelectric activity was defined as the migrating action potential complex (MAPC). ${ }^{1}$

Because both cholera toxin and ricinoleic acid may share in part common mechanisms regarding secretion, we wondered whether a similar motility component in our experimental model might be observed through the use of myoelectric recording techniques.

The purpose of this study was twofold: first, to investigate the effects of castor oil, ricinoleic acid, and ricinelaidic acid on the smooth muscle of the small intestine; and second, to investigate these effects, if any, for at least $6 \mathrm{~h}$ after exposure because the onset time of pharmacologic effect has been shown to range from 2 to $6 \mathrm{~h}$ in humans $(1,2)$.

\section{METHODS}

All studies were performed in male New Zealand white rabbits weighing between 1.5 and $3.0 \mathrm{~kg}$. The rabbits were anesthetized with pentobarbital sodium $(25 \mathrm{mg} / \mathrm{kg})$ given through an ear vein. Additional anesthetic was administered as needed through a catheter placed in the external jugular vein. A tracheostomy was performed in each animal. The terminal ileum was located through a midline abdominal incision.

\footnotetext{
${ }^{1}$ Abbreviation used in this paper: MAPC, migrating action potential complex.
} 
The first model that was used in all ileal loop studies consisted of the distal $12 \mathrm{~cm}$ of small intestine. Four monopolar silver-silver chloride electrodes were sewn to the serosal surface at $2.5-\mathrm{cm}$ intervals. Each electrode was connected to a rectilinear recorder (Beckman RM Dynograph, Beckman Instruments, Inc., Fullerton, Calif.) through AC couplers (9806A). Studies were performed with a time constant of $1.0 \mathrm{~s}$, a high-frequency cutoff of $22 \mathrm{~Hz}$, and a sensitivity of $0.5 \mathrm{mV} / \mathrm{cm}$. An indifferent electrode was placed in the subcutaneous tissue of a hind limb. Respirations were monitored through a pneumograph placed around the chest and attached to a pressure transducer (Statham P23BB, venous Statham Instruments Division, Gould, Inc. Oxnard, Calif.). The intra-abdominal temperature was measured with a centigrade thermometer upon opening the peritoneal cavity, and temperature was maintained at the same level throughout the experiment by means of a waterperfused heating blanket (Aquamatic K-pad, model K-1-5, Gorman-Rupp Industries Division, Bellville, Ohio). The orad end of the ileal loop was catheterized with a polyethylene tube (inside diameter, 0.030 in $[0.08 \mathrm{~cm}]$, outside diameter, 0.048 in $[0.13 \mathrm{~cm}])$ that was inserted through an ileal wall puncture wound, extended so that the tip was under the first electrode, and secured by a purse-string suture in addition to the loop ligature. The caudal end of the loop was catheterized by a second polyethylene tube (inside diameter, 0.187 in $[0.48 \mathrm{~cm}]$, outside diameter, 0.250 in $[0.64 \mathrm{~cm}])$ and secured by a loop ligature. The orad catheter was used for the administration of materials into the ileal loop. The caudal catheter was used for the outflow of intraluminal contents.

A second preparation that was used consisted of four sets of electrodes placed at specific areas on the small intestine and colon. 16 silver-silver chloride electrodes were sewn to the serosal surface. Four electrodes were equally placed at $2.5 \mathrm{-cm}$ intervals in the fourth part of the duodenum, in the mid-jejunum, the terminal ileum, and the sigmoid colon. A small polyethylene catheter was inserted through a duodenal wall puncture wound in the first part of the duodenum, as previously described. A larger polyethylene catheter was inserted distal to the terminal ileal electrodes, also as described.

After the preparation was completed, one of the following compounds was administered into the orad end of the ileal loop: (a) castor oil, $0.85 \mathrm{ml} / \mathrm{kg}$; $(b)$ an intraluminal infusion of ricinoleic acid, $2 \mu \mathrm{g} / \mathrm{kg}$ per min $(6 \mathrm{~m} \mathrm{MI})$; (c) a control infusion of ricinelaidic acid, $2 \mu \mathrm{g} / \mathrm{kg}$ per min; or $(d)$ an intraluminal perfusion of $0.9 \%$ sodium chloride solution, 1.14 $\mathrm{ml} / \mathrm{h}$. Both ricinoleic acid and ricinelaidic acid were diluted with $0.9 \%$ sodium chloride solution to a volume that would deliver $1.14 \mathrm{ml} / \mathrm{h}$. In the experiments designed to investigate the motor response in the segments of the duodenum, midjejunum, terminal ileum, and sigmoid colon simultaneously, $2 \mu \mathrm{g} / \mathrm{kg}$ per min of ricinoleic acid was perfused into the duodenum at a rate of $1.14 \mathrm{ml} / \mathrm{h}$. Bromosulfophthalein, 1 $\mathrm{ml}$ by bolus injection, was added into the duodenum of one animal at the onset of jejunal MAPC activity. The bromosulfophthalein dye was used as a marker of intraluminal flow. All myoelectric recordings were evaluated for the following: (a) slow wave frequencr; $(b)$ slow wave propagation velocity; (c) MAPC frequency; (d) the MAPC propagation velocity; and (e) the MAPC onset time. A full-thickness biopsy of the ileal loop was obtained at the end of each experiment, and the biopsy sample was placed in a $10 \%$ formaldehyde solution. The biopsy sample was then processed in a standard manner for hematoxylin-eosin staining and examined with a light microscope. The examination was performed in a blind fashion in the Depart- ment of Comparative Pathology, University of Florida College of Veterinary Medicine. The results were evaluated by a Student's $t$ test.

\section{RESULTS}

Fig. 1 illustrates the myoelectric pattern obtained from a perfusion of $2 \mu \mathrm{g} / \mathrm{kg}$ per min of ricinoleic acid into the orad end of the ileal loop. The myoelectric activity was similar to the MAPC observed in the cholera enterotoxin-infected loops. The term MAPC will be used to describe the myoelectric activity that has been observed in certain abnormal states. The MAPC has been defined as action potential discharge activity occurring for longer than $2.5 \mathrm{~s}$, on at least two consecutive electrode sites at $2.5-\mathrm{cm}$ intervals, and having a propagation velocity of $\cong 1.0 \mathrm{~cm} / \mathrm{s}$. Similar results were observed when castor oil, 0.85 $\mathrm{ml} / \mathrm{kg}$, was administered into the loop. No MAPC activity occurred in the loops perfused with ricinelaidic acid, $2 \mu \mathrm{g} / \mathrm{kg}$ per min, or in the control loops perfused with $0.9 \%$ sodium chloride solution at a similar perfusion rate. As reported (9), control experiments using bolus injections of $1.0,2.5,5.0$, or $10.0 \mathrm{ml}$ of water or $0.9 \%$ sodium chloride produced action potential discharge activity, but the action potential discharge activity did not fulfill the criteria for the MAPC.

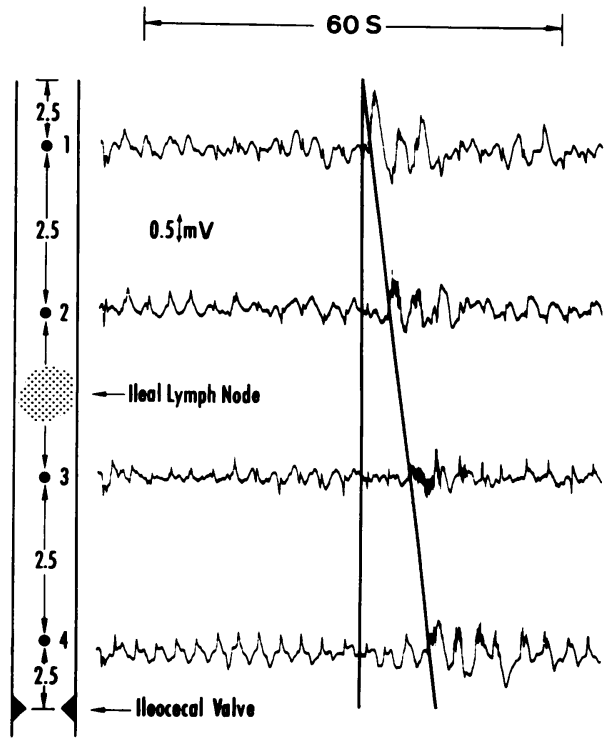

FIGURE 1 The migrating action potential complex (MAPC) from the perfusion of ricinoleic acid, $2 \mu \mathrm{g} / \mathrm{kg}$ per min $(6 \mathrm{mM})$ into an ileal loop. The electrode placement is illustrated schematically on the left. A time constant and sensitivity calibration are located on the upper aspect of the figure. The slope of the line on the right, as compared with the vertical reference line on the left, represents the propagation velocity of the MAPC. The propagation velocity of this complex was $0.91 \mathrm{~cm} / \mathrm{s}$. 
TABLE I

The Myoelectric Events for Castor Oil, and Infusions of Ricinoleic Acid and Ricinelaidic Acid

\begin{tabular}{|c|c|c|c|c|c|}
\hline & $\begin{array}{c}\text { Controls } \\
(\mathrm{NaCl}) \\
(n=3)\end{array}$ & $\begin{array}{l}\text { Castor oil* } \\
\quad(n=5)\end{array}$ & $\begin{array}{c}\text { Ricinoleic } \\
\text { acid }^{*} \\
(n=4)\end{array}$ & $\begin{array}{c}\text { Ricinoleic } \\
\text { acid } t \\
(n=4)\end{array}$ & $\begin{array}{c}\text { Ricinelaidic } \\
\text { acid* }^{*} \\
(n=4)\end{array}$ \\
\hline Slow wave frequency, cycles/min $\S$ & $17.30 \pm 2.90$ & $17.90 \pm 0.53$ & $18.20 \pm 1.03$ & $16.70 \pm 0.75$ & $17.10 \pm 0.28$ \\
\hline Slow wave propagation velocity, $\mathrm{cm} / \mathrm{s} \S$ & $1.14 \pm 0.14$ & $0.76 \pm 0.05$ & $0.74 \pm 0.10$ & $0.71 \pm 0.09$ & $0.72 \pm 0.01$ \\
\hline Number of MAPC/h" & none & $7.35 \pm 1.94$ & $8.32 \pm 2.85$ & $18.00 \pm 10.20$ & none \\
\hline MAPC propagation velocity, $\mathrm{cm} / \mathrm{s}$ & none & $0.85 \pm 0.12$ & $0.91 \pm 0.06$ & $0.70 \pm 0.05$ & none \\
\hline MAPC onset time, $h$ after exposure & none & $3.80 \pm 0.79$ & $2.70 \pm 0.53$ & $4.10 \pm 1.30$ & none \\
\hline
\end{tabular}

Results are mean \pm SEM.

* Ileal loop preparations.

$\$$ Ileal responses to duodenal infusions.

$\$$ No significant difference from controls $(P>0.05)$.

"No significant difference in the values for the MAPC observed with castor oil and ricinoleic acid perfused into the ileal loops and to first part of the duodenum.

Table I illustrates the values of the myoelectric activity for the ileal loops exposed to castor oil, ricinoleic acid, and ricinelaidic acid. The values for the number of MAPCs per hour, MAPC propagation velocity, and MAPC onset time were similar for the loops exposed to castor oil, the ileal loops perfused with ricinoleic acid, and the ileal responses to the duodenal perfusions with ricinoleic acid. Fig. 2 illustrates a representative recording from the jejunum and ileum during administration of ricinoleic acid into the duodenum. Migrating action potential complexes were observed in the mid-jejunum (Fig. 2) and terminal ileum (Fig. 3). Besides the MAPC activity observed

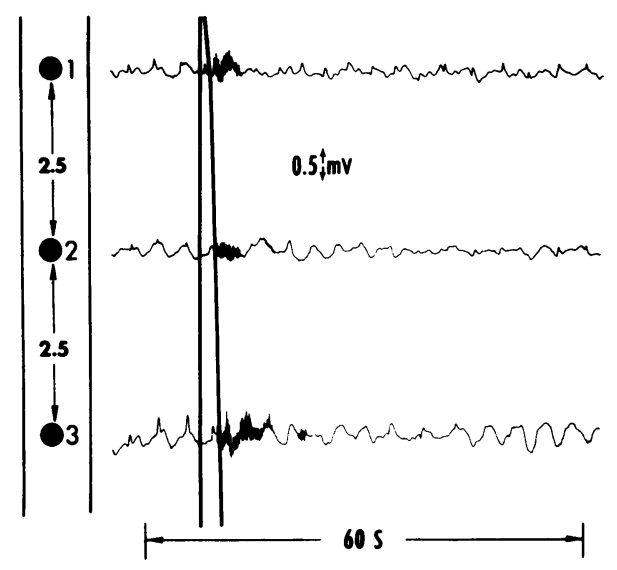

Figure 2 The myoelectric complex in the mid-jejunum was in response to perfusion of ricinoleic acid, $2 \mu \mathrm{g} / \mathrm{kg}$ per $\min (6 \mathrm{mM})$, into the first part of the duodenum. The electrode placement is illustrated schematically on the left. A time constant and sensitivity calibration are located on the upper aspect of the figure. The propagation velocity illustrated by the slope of the line on the right, as compared with the vertical reference line on the left, was 0.87 $\mathrm{cm} / \mathrm{s}$. This is similar to the propagation velocity noted for the MAPC observed in the ileum. in the terminal ileum, intermittent spiking on additional slow waves was also observed. This additional activity was not observed in the cholera-infected loops. Little-to-no action potential activity ever occurred in the duodenum or sigmoid colon. No MAPC activity occurred in control experiments in which $0.9 \%$ sodium chloride solution was perfused into the duodenum at the rate of $1.14 \mathrm{ml} / \mathrm{h}$. When compared with loops exposed to a $0.9 \%$ sodium chloride infusion, there was no statistical difference in the slow wave frequency or slow wave propagation velocity in the loops exposed to castor oil, ricinoleic acid, or ricinelaidic acid. The biopsy of the ileal loops at the end of each

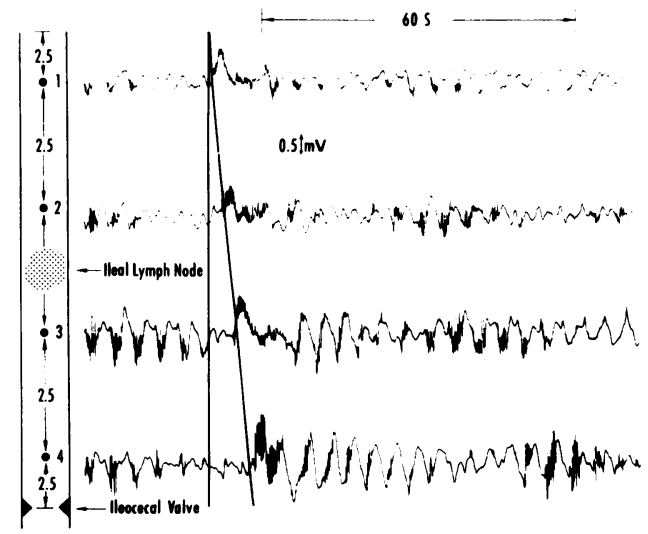

Figure 3 The myoelectric complex in the terminal ileum was in response to a perfusion of ricinoleic acid, $2 \mu \mathrm{g} / \mathrm{kg}$ per $\min (6 \mathrm{mM})$, into the first part of the duodenum. The electrode placement is illustrated schematically on the left. A time constant and sensitivity calibration are noted at the upper aspect of the figure. The propagation velocity of the MAPC illustrated by the slope of the line on the right, as compared with the vertical reference line on the left, was $0.91 \mathrm{~cm} / \mathrm{s}$. In addition to the MAPC, additional random action potential discharge activity was noted on several slow waves preceding and following the MAPC. 
experiment revealed no alteration in intestinal structure when examined under a light microscope. Each of the biopsies from the ileal loops was examined in a blind fashion by Dr. Shields.

\section{DISCUSSION}

A current review has stressed the need for a reclassification of laxatives based on their "specific mechanism of action" (8). The classification of laxatives varies depending on the reference that is read $(1,2)$. A recent submission by an advisory panel to the Food and Drug Administration classifies laxatives into five categories: (a) an irritant or stimulant; $(b)$ wetting agents; $(c)$ saline; $(d)$ bulk; $(e)$ lubricant compounds (14). The compounds that encompass the category of the irritant or stimulant alter glucose and electrolyte transport with a concomitant water flux $(3-6,15-20)$. It was suggested that this alteration may be through a mechanism similar to that of cholera toxin (21). This concept has been challenged recently by several investigators who have shown changes in the villous tips and an increased permeability to inulin and 1,600 mol wt dextran in response to $8 \mathrm{mM}$ ricinoleic acid (8). Gaginella and co-workers $(9,10)$ demonstrated that when they used $10 \mathrm{mM}$ of ricinoleic acid, no alteration of the tight junctions occurred. Thus, the secretory mechanism may be mediated through several mechanisms.

Fingel (1) and Bonnycastle (2) have reported that ricinoleic acid and its associated compounds irritated the smooth muscle. But there have been no studies showing that ricinoleic acid stimulates intestinal motor function when the mucosal surface is exposed to the acid.

Recently it has been questioned whether any of the irritant or stimulant compounds can induce motor activity at all (11). Studies using strain gauge recording techniques reported that castor oil and its active ingredient, ricinoleic acid, inhibited circular smooth muscle of the small intestine of dogs $(22,23)$. Data analysis was limited to the first 2 -h period after the administration of the ricinoleic acid. In addition, circular smooth muscle was inhibited by ricinoleic acid in the cat colon (24). Our concern was that an active motility component existed but may have occurred beyond the reported 2 -h period. We have previously demonstrated that an abnormal myoelectric pattern developed in terminal ileal loops of the New Zealand white rabbit when exposed to cholera enterotoxin (12). In addition, we have reported that a lag period existed before the onset of MAPC activity to cholera enterotoxin $(3.8 \mathrm{~h})$ and to prostaglandin $\mathrm{F}_{2} \alpha(3.2 \mathrm{~h})(13)$. The presence of the lag period remains unexplained at this time. However, because $3^{\prime}, 5^{\prime}$ cyclic AMP may mediate some or all of the effects of both cholera enterotoxin $(25,26)$ and ricinoleic acid (3), it seemed probable that a similar motor event may exist for both compounds. However, others would question the role of $3^{\prime}, 5^{\prime}$ cyclic AMP in its association with ricinoleic acid-induced secretory effects $(4-6)$. The data in the present study indicate that an alteration in myoelectric activity does exist in response to castor oil and ricinoleic acid in the small intestine of the New Zealand white rabbits. The mean onset time for ricinoleic acid perfusion was $2.7 \mathrm{~h}$ and for castor oil, $3.8 \mathrm{~h}$. These times did not appreciably differ from the onset time for cholera. In addition, this lag period correlates well with the onset time observed for a clinical response in man $(1,2)$.

We suggest that our findings differ on three bases from those reported: First, because of the lag period before organized activity begins, investigators could have been misled to believe that motor activity was absent or decreased. Only recordings taken after the onset of MAPC activity would have shown the presence of a specific alteration in myoelectric activity. Second, the complexes were intermittent, intense, and organized. Little action potential activity occurred between the MAPCs. Thus, if one used a "motility index," or expressed data as the number of slow waves having associated action potential activity per unit of time, decreased activity could be suggested. And, third, our findings could represent species variation in the response of the smooth muscle of the small intestine to ricinoleic acid.

In the four additional experiments designed to investigate myoelectric activity in the duodenum, midjejunum, terminal ileum, and sigmoid colon, three interesting observations were made: $(a)$ Bromosulfophthalein dye, used as a marker of intraluminal flow was present in the intraluminal fluid obtained from the terminal outflow catheter with the onset of the first ileal MAPC. This observation reflects the distance over which the MAPC may travel in a relatively short period of time. (b) Jejunal MAPC activity occurred in addition to the complex activity observed in the terminal ileum. (c) No activity occurred in the sigmoid colon, a recording site well beyond the distal terminal ileal ligature. If activity had occurred in the sigmoid colon, one would have to speculate on several mechanisms. These may include the transmission of the message by alternate neural pathways, partial absorption of ricinoleic acid (6), or the release of a gastrointestinal hormone (9). The absence of any activity from the electrodes in the sigmoid colon suggests that none of the aforementioned mechanisms were involved. We have previously shown that the MAPC of cholera was mediated through an intrinsic myoneural reflex arc (13). We suggest that the MAPC activity observed with ricinoleic acid is on a similar basis. 


\section{ACKNOWLEDGMENTS}

We would like to thank sincerely Mrs. Alice Cullu, Mrs. Majorie Rider, and Mrs. Frances Tucker for their editorial and secretarial assistance in preparing this manuscript.

This work was supported by Medical Research Service of the Veterans Administration and the College of Medicine, University of Florida, Gainesville, Fla.

\section{REFERENCES}

1. Fingel, E. 1970. Cathartics and laxatives. In The Pharmacological Basis of Therapeutics. L. S. Goodman and A. Gilman, editors. Macmillan Publishing Co., New York. 10201024 .

2. Bonnycastle, D. D. 1971. Cathartics and laxatives. In Drill's Pharmacology in Medicine. J. R. DiPalma, editor. McGraw-Hill, Inc., New York. 911-975.

3. Bright-Asare, P., and H. J. Binder. 1973. Stimulation of colonic secretion of water and electrolytes by hydroxy fatty acids. Gastroenterology. 64: 81-88.

4. Ammon, H. V., and S. F. Phillips. 1974. Inhibition of ileal water absorption by intraluminal fatty acids. Influence of chain length, hydroxylation, and conjugation of fatty acids. J. Clin. Invest. 53: 205-210.

5. Ammon, H. V., P. J. Thomas, and S. F. Phillips. 1974. Effects of oleic and ricinoleic acids on net jejunal water and electrolyte movement. Perfusion studies in man. J. Clin. Invest. 53: 374-379.

6. Ammon, H. V., and S. F. Phillips. 1973. Inhibition of colonic water and electrolyte absorption by fatty acids in man. Gastroenterology. 65: 744-749.

7. Mekhjian, H. S., and S. F. Phillips. 1970. Perfusion with canine colon and unconjugated bile acids: effect on water and electrolyte transport, morphology and bile acid absorption. Gastroenterology. 59: 120-129.

8. Cline, W. S., V. Lorenzsonn, L. Benz, P. Bass, and W. A. Olsen. 1976. The effects of sodium ricinoleate on small intestinal function and structure. J. Clin. Invest. 58: $380-390$.

9. Gaginella, T. S., and S. F. Phillips. 1976. Ricinoleic acid (castor oil) alters intestinal surface structure: A scanning electronmicroscopic study. Mayo Clin. Proc. 51: 6-12.

10. Gaginella, T. S., J. C. Lewis, and S. F. Phillips. 1976. Ricinoleic acid effects on rabbit intestine. An ultrastructural study. Mayo Clin. Proc. 51: 569-573.

11. Binder, H. J., and M. Donowitz. 1975. Clinical trends and topics: A new look at laxative action. Gastroenterology. 69: 1001-1005.

12. Mathias, J. R., G. M. Carlson, A. J. DiMarino, G. Bertiger, H. E. Morton, and S. Cohen. 1976. Intestinal myoelectric activity in response to live Vibrio cholera and cholera enterotoxin. J. Clin. Invest. 58: 91-96.
13. Mathias, J. R., G. M. Carlson, A. J. Dimarino, G. Bertiger, and S. Cohen. 1976. The effect of cholera toxin on ileal myoelectric activity: a neural-hormonal mechanism. In The Proceedings of the Fifth International Symposium on Gastrointestinal Motility. G. Vantrappen, editor. Typoff-Press, Herentals, Belgium. 219-226.

14. Food and drug administration over-the-counter drugs: proposal to establish monographs for OTC laxative, antidiarrheal, emetic and antiemetic products. 1975. Fed. Regist. 40: 903-912, 944.

15. Nell, G., H. Overhoff, W. Forth, H. Kulenkampff, W. Specht, and W. Rummel. 1973. Influx and efflux of sodium in jejunal and colonic segments of rats under the influence of oxyphenisatin. Naunyn-Schmiedeberg's Arch. Pharmacol. 277: 53-60.

16. Ewe, K., and B. Holker. 1974. Einflub eines diphenolischen Laxans (Bisacodyl) aug den Wasser-und Electrolyttransport im menschlichen Colon. Klin. Wochenschr. 52: 827-833.

17. Ewe, K. 1972. Effect of laxatives on intestinal water and electrolyte transport. Eur. J. Clin. Invest. 2: 283. (Abstr.)

18. Phillips, R. A., A. H. G. Love, T. G. Mitchell, and E. M. Neptune. 1965. Cathartics and the sodium pump. Nature (Lond.). 206: 1367-1368.

19. Chignell, C. F. 1968. The effect of phenolphthalein and other purgative drugs on rat intestinal $\left(\mathrm{Na}^{+} \mathrm{K}^{+}\right)$ adenosine triphosphatase. Biochem. Pharmacol. 17: $1207-1212$.

20. Hart, S. L., and I. McColl. 1967. The effect of purgative drugs on the intestinal absorption of drugs. J. Pharm. Pharmacol. 19: 70-71.

21. Binder, H. J. 1974. Cyclic adenosine monophosphate controls bile salt and hydroxy fatty acid-induced colonic electrolyte secretion. J. Clin. Invest. 53: 7a-8a. (Abstr.)

22. Stewart, J. J., and P. Bass. 1976. Effects of ricinoleic and oleic acids on the digestive contractable activity of the canine small and large bowel. Gastroenterology. 70: $371-376$.

23. Stewart, J. J., T. S. Gaginella, W. A. Olsen, and P. Bass. 1975. Inhibitory actions of laxatives on motility and water and electrolyte transports in the gastrointestinal tract. J. Pharmacol. Exp. Ther. 192: 458-467.

24. Christensen, J., and B. W. Freeman. 1972. Circular muscle electromyogram in the cat colon: local effect of sodium ricinoleate. Gastroenterology. 63: 1011-1015.

25. Field, M., M. Fromm, Q. Al-Awqati, and W. B. Greenough, III. 1972. Effect of cholera enterotoxin on ion transport across isolated ileal mucosa. J. Clin. Invest. 51: 796-804

26. Kimberg, D. V., M. Field, J. Johnson, A. Henderson, and E. Gershon. 1971. Stimulation of intestinal mucosal adenyl cyclase by cholera enterotoxin and prostaglandins. J. Clin. Invest. 50: 1218-1230. 